\title{
Prolonged-release nicotinic acid for the management of dyslipidemia: an update including results from the NAUTILUS study
}

\author{
Anja Vogt' \\ Ursula Kassner ${ }^{1}$ \\ Ulrike Hostalek ${ }^{2}$ \\ Elisabeth Steinhagen-Thiessen' \\ 'Charite-Universitatsmedizin Berlin, \\ Germany; ${ }^{2}$ Merck KGaA, Darmstadt, \\ Germany
}

\begin{abstract}
Low HDL-cholesterol $(<1.02 \mathrm{mmol} / \mathrm{L}$ [40 mg/dL] in men or $<1.29 \mathrm{mmol} / \mathrm{L}$ [50 mg/dL] in women) occurs in about one-third of European patients with dyslipidemia and is an independent cardiovascular risk factor. Simultaneous correction of low HDL-cholesterol and high totalcholesterol and LDL-cholesterol may provide reductions in cardiovascular morbidity and mortality beyond those possible with statins alone. Nicotinic acid (niacin in the US) is the most effective means of increasing HDL-cholesterol available and has been shown to reduce cardiovascular event rates significantly. Niaspan ${ }^{\circledR}$ (prolonged-release nicotinic acid) provides a convenient, once-daily means of administering nicotinic acid. Clinical studies with Niaspan ${ }^{\circledR}$ have demonstrated marked, long-term increases in HDL-cholesterol with additional useful benefits on triglycerides, LDLcholesterol, and lipid sub-profiles. The NAUTILUS study demonstrated the beneficial efficacy and tolerability profiles of Niaspan ${ }^{\circledR}$ in a usual-care setting. The most common side-effect of Niaspan ${ }^{\circledR}$ is flushing, which infrequently causes treatment discontinuation and which usually subsides over continued treatment. The ARBITER 2 and ARBITER 3 studies showed 1-2 years of treatment with Niaspan ${ }^{\circledR}$ plus a statin induced regression of atherosclerosis in patients with coronary artery disease. The effect of Niaspan ${ }^{\circledR}$-statin treatment, relative to a statin alone, on clinical cardiovascular outcomes is currently under evaluation. Niaspan ${ }^{\circledR}$ represents a practical means of correcting low HDL-cholesterol, an independent risk factor for adverse cardiovascular outcomes.

Keywords: prolonged-release nicotinic acid, Niaspan ${ }^{\circledR}$, niacin, dyslipidemia, HDL-cholesterol cardiovascular risk
\end{abstract}

\section{Introduction}

Cardiovascular disease remains the main cause of mortality in developed nations, and an increasing tendency towards urbanization, adoption of western lifestyles, and obesity threatens a substantial future burden of cardiovascular morbidity and mortality in developing nations (Dominguez et al 2006; Raymond et al 2006). It is necessary to maximize the use of all cardiovascular management strategies to address this challenge adequately. Dyslipidemia remains an important source of elevated cardiovascular risk and is heterogeneous in presentation, with elevated ApoB-containing lipoproteins (eg, LDL-cholesterol) and/or low HDL-cholesterol commonly observed. Moreover, patients with conditions often associated with insulin resistance, such as type 2 diabetes, the metabolic syndrome, or abdominal obesity, often present with a characteristic dyslipidemic phenotype that includes low HDL-cholesterol in the presence of normal or near-normal LDL-cholesterol (Niskanen et al 1998; Goldberg 2001; Hansel et al 2004). This phenotype predicts an increased risk of adverse cardiovascular outcomes. This is caused by the accumulation of triglyceride-rich remnants and by the more atherogenic small LDL-particles associated with the metabolic syndrome and, on the other hand, 
by the reduced cardiovascular protection resulting from low levels of HDL-cholesterol (Niskanen et al 1998).

In the prevention of cardiovascular disease, even intensive intervention with a statin, achieving levels of LDL-cholesterol well below those recommended by current cardiovascular management guidelines, has failed to reduce cardiovascular event rates by more than about $20 \%-40 \%$ relative to placebo (reviewed by Kastelein 2005). Since HDL-cholesterol is an important cardiovascular risk factor, addressing both hypercholesterolemia and low HDLcholesterol is a rational clinical strategy for patients with these lipid abnormalities. Strategies are available to achieve these twin goals: HMG-CoA reductase inhibitors (statins) provide effective control of LDL-cholesterol and nicotinic acid (known as niacin in the USA) is the most powerful agent available for the correction of low HDL-cholesterol (Expert Panel 2001). Niaspan ${ }^{\circledR}$ is a once-daily, prolonged-release formulation of nicotinic acid which is indicated in many areas for the correction of low HDL-cholesterol. Current US and European management guidelines, however, focus strongly on control of LDL-cholesterol as the primary focus of cardiovascular care (Expert Panel 2001; Third Joint Task Force 2003). Accordingly, this review not only summarizes the therapeutic profile of Niaspan ${ }^{\circledR}$, but also discusses the substantial evidence base supporting the clinical potential of correcting low HDL-cholesterol.

\section{Why we should correct low HDL-cholesterol \\ Low HDL-cholesterol is an independent cardiovascular risk factor}

The Framingham Study identified low HDL-cholesterol as an independent risk factor for adverse cardiovascular outcomes more than three decades ago (Gordon et al 1977). This landmark study defined a significant association $(\mathrm{p}<$ 0.001) between low HDL-cholesterol and a range of cardiovascular endpoints in men and women during 4 years of follow-up. Importantly, the increased cardiovascular risk associated with low HDL-cholesterol was greater than that associated with elevated LDL-cholesterol, and persisted after adjustment for other lipid parameters and cardiovascular risk factors. Further analyses from this landmark study, involving up to 12 years of follow-up, have confirmed that low HDL-cholesterol increases cardiovascular risk over the long term, with an approximate 4-fold increase in the risk of cardiovascular or coronary death, and an approximate doubling of the risk of death from any cause (Castelli et al 1986; Wilson et al 1988). The 10-year Atherosclerosis Risk in Communities (ARIC) study also demonstrated an independent and significant influence of low HDL-cholesterol on cardiovascular risk in a North American population (Sharrett et al 2001). A pooled analysis of Framingham and three other major North American trials (the Lipid Research Clinics Prevalence Mortality Follow-up Study, the Coronary Primary Prevention Trial and the Multiple Risk Factor Intervention Trial) showed that for each decrease in HDL-cholesterol of $0.03 \mathrm{mmol} / \mathrm{L}(1 \mathrm{mg} / \mathrm{dL})$, the risk of coronary heart disease increased by $2 \%$ in men and by $3 \%$ in women (Gordon et al 1989).

Similar associations between low HDL-cholesterol and cardiovascular risk hold in other populations. A large observational study in Germany, the PROspective CArdiovascular Münster (PROCAM) Study, showed that subjects with low HDL-cholesterol had an approximately four-fold increase in the risk of coronary heart disease, compared with subjects with normal HDL-cholesterol levels, consistent with the results from Framingham (Assmann et al 1996). A study in a population of German type 2 diabetes patients undergoing coronary angiography used factor analysis to determine the elements of the lipid profile that were most significantly associated with adverse cardiovascular outcomes during subsequent follow up (Drexel et al 2005). Factor analysis is a statistical technique that analyses the effects of a large number of variables and expresses their overall effects in terms of a smaller number of key variables, termed factors. In this way, factor analysis reveals the underlying driving forces behind complex phenomena. This analysis identified two distinct factors: one, related to HDL-cholesterol, was significantly associated with coronary atherosclerosis, while another factor, related to LDL-cholesterol, was not.

A study in the UK demonstrated a significant inverse association between the level of HDL-cholesterol and the risk of ischemic heart disease, but found that this was not independent of other cardiovascular risk factors (Pocock et al 1989). However, a re-analysis of these data in a manner consistent with the US studies described above (in terms of covariates used) revealed a consistent inverse relationship between HDL-cholesterol levels and coronary risk (Gordon et al 1989). A further study from the UK found an independent inverse relationship between levels of HDL-cholesterol (particularly the HDL2 sub-fraction) and the severity of angiographically defined coronary stenoses (Miller et al 1981). The UK Prospective Diabetes Study identified HDL-cholesterol as the second most important risk factor for coronary artery disease during 10 years of 
follow-up of newly-diagnosed type 2 diabetes patients (Turner et al 1998). In a population of more than 8000 Israeli subjects without prior coronary disease followed for 21 years, low HDL-cholesterol $(<0.9 \mathrm{mmol} / \mathrm{L}$ [35 mg/dL]) was associated with an increase in coronary mortality of about 20\%-25\% (Goldbourt et al 1997). Finally, the large, international Interheart case-control study found that a high ApoB:ApoAI ratio accounted for more than half of the population-attributable risk of a first myocardial infarction (Yusuf et al 2004).

It is important to note that the prognostic significance of low HDL-cholesterol is similar whether or not LDLcholesterol is elevated. Data from the Framingham study suggest that, on average, the risk of coronary heart disease in a patient with elevated LDL-cholesterol $(5.7 \mathrm{mmol} / \mathrm{L}$ [220 mg/dL]) and normal HDL-cholesterol (1.2 mmol/L [45 mg/dL]) is comparable with the risk in a patient with well-controlled LDL-cholesterol $(2.6 \mathrm{mmol} / \mathrm{L}$ [100 mg/ $\mathrm{dL}])$ and low HDL-cholesterol (0.6 mmol/L [25 mg/dL]) (Gordon et al 1977; Castelli et al 1988). Moreover, the long-term observational study in Israeli subjects stratified patients on the basis of their levels of HDL-cholesterol and total cholesterol (Goldbourt et al 1997). High cholesterol $(>5.2 \mathrm{mmol} / \mathrm{L}[213 \mathrm{mg} / \mathrm{dL}])$ increased the risk of death from coronary heart disease, as would be expected; nevertheless, the excess risk associated with low HDL-cholesterol ( $\leq 0.9 \mathrm{mmol} / \mathrm{L}[35 \mathrm{mg} / \mathrm{dL}]$ ) was essentially the same in the high- and low-cholesterol groups (Figure 1).

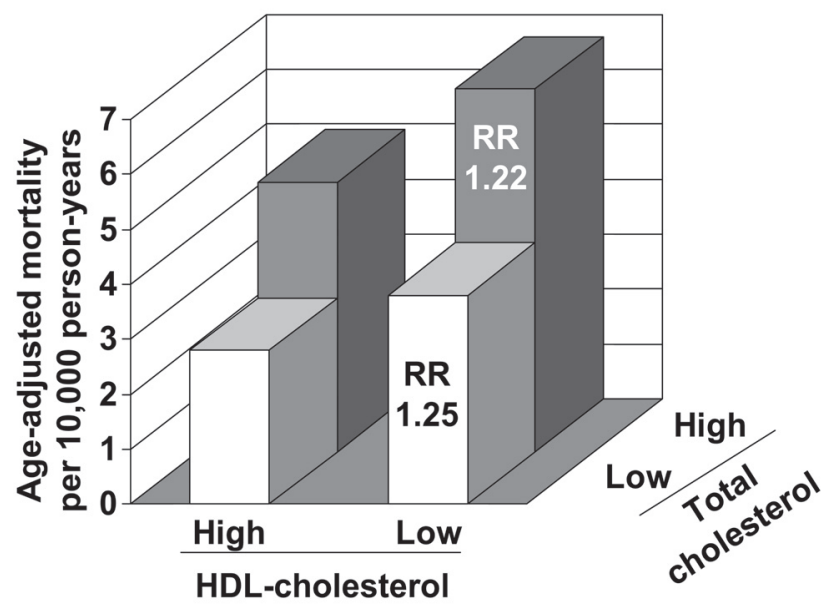

Figure I Adjusted coronary heart disease mortality rates according to HDL-cholesterol and LDL-cholesterol levels during 21 years of follow-up in 8586 Israeli men without coronary heart disease at baseline. Cut-off values to define low/high lipid levels were $0.9 \mathrm{mmol} / \mathrm{L}$ for $\mathrm{HDL}$-cholesterol and $5.2 \mathrm{mmol} / \mathrm{L}$ for total-cholesterol. RR: risk ratios compared with corresponding low HDL-cholesterol group (adjusted for age, systolic blood pressure, smoking, and diabetes). Drawn from data presented by Goldbourt et al (1997).

\section{High prevalence of low HDL-cholesterol despite lipid-modifying intervention}

Prevalence estimates from various countries suggest a substantial prevalence of low HDL-cholesterol. Data from the PROCAM study demonstrated a prevalence of low HDL-cholesterol $(<0.9 \mathrm{mmol} / \mathrm{L}[35 \mathrm{mg} / \mathrm{dL}]$ for men and $<1.2 \mathrm{mmol} / \mathrm{L}[45$ $\mathrm{mg} / \mathrm{dL}$ ] for women) of $13 \%-16 \%$ in men and $18 \%-20 \%$ in women, depending on age (Assmann et al 1996). Moreover, a markedly higher prevalence of low HDL-cholesterol was observed in patients with coronary heart disease (45.2\%) relative to those without (16.1\%) (Assmann et al 1996). Analysis of data from general populations of 5 European countries showed that HDL-cholesterol $<0.90 \mathrm{mmol} / \mathrm{L}(35 \mathrm{mg} / \mathrm{dL})$ in men or $<1.01$ $\mathrm{mmol} / \mathrm{L}(<39 \mathrm{mg} / \mathrm{dL})$ in women was present in $7 \%-24 \%$ of subjects (Balkau et al 2002). Data from the National Health and Nutrition Examination Survey in the USA demonstrated an age-adjusted prevalence of HDL-cholesterol $<1.02 \mathrm{mmol} / \mathrm{L}$ $(40 \mathrm{mg} / \mathrm{dL})$ in men of $35.2 \%$ and $<1.29 \mathrm{mmol} / \mathrm{L}(50 \mathrm{mg} / \mathrm{dL})$ in women of $39.3 \%$ (Ford et al 2002). While these data were sufficient to arouse concern, differences in the definitions of low HDL-cholesterol between studies, and different survey methodologies and recruitment criteria precluded the quantification of the magnitude of the problem posed by low HDL-cholesterol.

The Pan-European Survey of HDL-cholesterol was designed to address this problem by generating a reliable estimate of the prevalence of low HDL-cholesterol in patients being managed for dyslipidemia across 11 countries in Europe (Bruckert et al 2005a, b). Low HDL-cholesterol was defined as a level below $1.03 \mathrm{mmol} / \mathrm{L}(40 \mathrm{mg} / \mathrm{dL})$ in men and $1.29 \mathrm{mmol} / \mathrm{L}(50 \mathrm{mg} / \mathrm{dL})$ in women, in a manner consistent with cardiovascular management guidelines. In total, 8545 patients were included in the analysis; about one-third of patients had low HDL-cholesterol, and about one-fifth of patients had a potentially atherogenic combination of low HDL-cholesterol and elevated triglycerides (Table 1). Importantly, the prevalence of low HDL-cholesterol was similar whether or not patients were being actively treated for dyslipidemia (mainly with statins). A further analysis in 3866 type 2 diabetes patients within the survey population revealed a higher prevalence of low HDL-cholesterol in this population (45\%) (Bruckert et al 2007). These data demonstrate that low HDLcholesterol is not only prevalent among the general population of patients with dyslipidemia, but is under-treated.

\section{Correcting low HDL-cholesterol improves cardiovascular outcomes}

A number of studies have demonstrated clinically significant cardiovascular benefits from pharmacologic 
Table I Prevalence of low HDL-cholesterol in the Pan-European Survey of HDL-cholesterol (Bruckert et al 2005a)

\begin{tabular}{lll}
\hline & Receiving lipid-modifying treatment & No lipid-modifying treatment \\
\hline Low HDL-cholesterol (\%) & 32.5 & 34.4 \\
$\quad$ Men & 39.9 & 38.5 \\
Women & & 26.3 \\
Low HDL-cholesterol and high triglycerides (\%) & 21.2 & 26.9 \\
Men & 24.9 & \\
Women &
\end{tabular}

Notes: Low HDL-cholesterol: < $1.03 \mathrm{mmol} / \mathrm{L}$ (men), < I.29 mmol/L (women); high triglycerides: > I.69 mmol/L (men and women).

intervention to increase levels of HDL-cholesterol in patients with coronary artery disease. Again, this knowledge has been available for more than 3 decades, since the demonstration of reduced all-cause mortality in hypercholesterolemic patients randomized to receive immediate-release nicotinic acid or placebo in the Coronary Drug Project (CDP) in 1975 (CDP 1975). A re-analysis of the data from the CDP has shown that the cardiovascular benefit arising from nicotinic acid was still present 15 years after the conclusion of the trial, ie, 9 years after the end of double-blind follow-up within the study (Canner et al 1986). Other new analyses from this trial have demonstrated that the benefit from nicotinic acid extended to subgroups of patients with the metabolic syndrome or dysglycemia (Canner et al 2005, 2006). Nicotinic acid also improves outcomes when combined with a statin: the HDL Atherosclerosis Treatment Study (HATS) demonstrated a 90\% relative risk reduction vs placebo in a composite cardiovascular endpoint (death, myocardial infarction, stroke or revascularization) (Brown et al 2001). A beneficial effect on atherosclerosis progression measured by angiography was observed in HATS, and in other trials evaluating immediate-release nicotinic acid-based combination regimens, consistent with the observed outcome benefits described above (Brown et al 1990; Kane et al 1990; Whitney et al 2005). Intervention trials using a fibrate to increase HDL-cholesterol have also yielded significant anti-atherosclerotic benefits or improvements in cardiovascular event rates (Frick et al 1987; CashinHemphill et al 1990; Rubins et al 1999). The Fenofibrate Intervention and Event Lowering in Diabetes (FIELD) study, a randomized trial of fenofibrate vs. placebo in patients with type 2 diabetes, did not yield a significant reduction in cardiovascular event rates (Keech et al 2005). However, while there was a substantial reduction in triglycerides in the fibrate group at study end, there was essentially no effect on HDL-cholesterol. Therefore, the negative outcome of this trial does not diminish the status of low HDL-cholesterol as a cardiovascular risk factor.

\section{The therapeutic rationale for Niaspan ${ }^{\circledR}$}

The information presented in the previous section clearly supports the principle of intervention to correct low HDLcholesterol. US cardiovascular management guidelines compare the efficacy of different lipid-modifying treatments and identify nicotinic acid as the most potent agent available for this purpose (Expert Panel 2001). Perceived drawbacks to the use of nicotinic acid have limited its use in routine clinical practice, however, including concern over a high incidence of flushing, potential for hepatotoxicity and exacerbation of dysglycemia.

The therapeutic profile of formulations of nicotinic acid depends on its metabolism, which proceeds via two distinct biochemical pathways (Pieper 2002). The first is a pathway with high affinity, but a low capacity, for nicotinic acid which is linked to hepatotoxicity and the second is a low-affinity but high capacity pathway, which is linked to flushing. An oral dose of immediate-release nicotinic acid causes a large but relatively brief surge in plasma nicotinic acid levels. This saturates the low capacity pathway, and a relatively high flux through the second pathway causes the flushing commonly observed with nicotinic acid. Previous attempts at the development of slow-release nicotinic acid preparations, with consequently lower plasma nicotinic acid concentrations, reduced the potential for flushing, but led to more metabolism via the low-capacity pathway over a longer period of time. This resulted in unacceptable hepatotoxicity (Dalton and Berry 1992).

Niaspan ${ }^{\circledR}$ was designed to deliver nicotinic acid at a rate intermediate between the immediate release and earlier sustained-release formulations, and delivers the drug over a period of approximately $8-12$ hours (Pieper 2002). In this way, Niaspan ${ }^{\circledR}$ was intended to minimize the potential of 
both hepatotoxicity and flushing. The efficacy safety and tolerability profiles of Niaspan ${ }^{\circledR}$ are discussed in detail in the following section.

\section{Lipid-modifying efficacy of Niaspan ${ }^{\circledR}$ Niaspan ${ }^{\circledR}$ administered as monotherapy}

The effects of Niaspan ${ }^{\circledR}$ on HDL-cholesterol are essentially identical to those of immediate-release nicotinic acid. This was demonstrated by a double-blind clinical trial in patients with primary dyslipidemia randomized to receive once-daily Niaspan ${ }^{\circledR} 1500 \mathrm{mg}(\mathrm{n}=76)$, immediate-release nicotinic acid $1500 \mathrm{mg}(\mathrm{n}=74)$ or placebo $(\mathrm{n}=73)$ for 8 weeks (Knopp et al 1998). Average percentage changes in HDL-cholesterol in the intention-to-treat efficacy analysis at 8 weeks were $18.2 \%$ for Niaspan $^{\circledR}, 18.7 \%$ for immediate-release nicotinic acid and $0.4 \%$ for placebo $(\mathrm{p}<0.05 \mathrm{vs}$ either nicotinic acid formulation). Similar reductions for Niaspan ${ }^{\circledR}$ and immediaterelease nicotinic acid occurred for LDL-cholesterol $(-12 \%$ change for each formulation) and triglycerides $(-15 \%$ and $-17 \%$, respectively), with no significant differences between these groups.

Two other double-blind, placebo-controlled trials evaluated the relationship between the dosage of Niaspan ${ }^{\circledR}$ given as monotherapy and changes in lipid parameters. One study involved randomization of patients with dyslipidemia to placebo $(n=44)$ or $\operatorname{Niaspan}^{\circledR}(n=87)$, with daily doses increased from $500 \mathrm{mg}$ to $3000 \mathrm{mg}$ at intervals of 4 weeks (Goldberg et al 2000). Changes in lipid parameters in the placebo group were minimal. In contrast, treatment with all doses of Niaspan ${ }^{\circledR}$ was associated with significant increases in HDL-cholesterol relative to placebo, up to a maximum increase of about $30 \%$ relative to baseline at doses of 2500 $3000 \mathrm{mg}$. The marked and significant decreases in triglycerides and LDL-cholesterol evident in Figure 2 are typical effects of nicotinic acid and may provide useful additional benefits on the overall lipid profile. The second evaluation of different doses of Niaspan ${ }^{\circledR}$ monotherapy was a randomized comparison of $\mathrm{Niaspan}^{\circledR} 1000 \mathrm{mg}(\mathrm{n}=41)$, Niaspan ${ }^{\circledR} 2000 \mathrm{mg}$ $(n=41)$ and placebo $(n=40)$, each administered for 16 weeks to patients with hypercholesterolemia (Morgan et al 1996). Percentage changes from baseline in HDL-cholesterol with these treatments were $17 \%, 23 \%$, and $4 \%$, respectively. Corresponding changes in triglycerides were $-21 \%,-29 \%$, and $3 \%$, respectively, and changes in LDL-cholesterol were $-6 \%$, $-14 \%$, and $0 \%$, respectively. Changes in all parameters at either dose were significant relative to placebo $(\mathrm{p}<0.05)$.

Most of these studies also demonstrated significant reductions in the atherogenic lipoprotein, $\mathrm{Lp}(\mathrm{a})$, which is

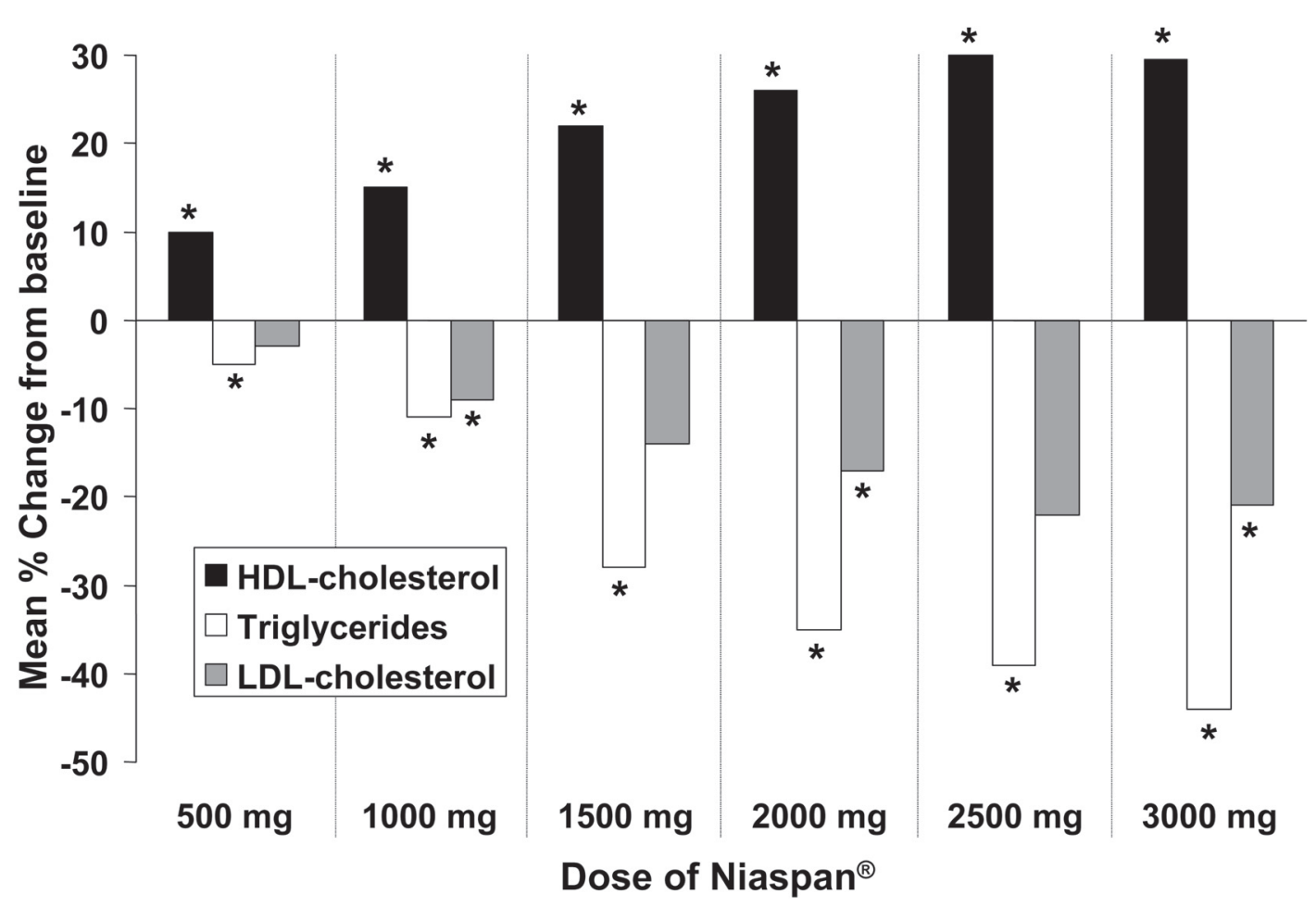

Figure 2 Dose-related effect of Niaspan ${ }^{\circledR}(500-3000 \mathrm{mg} /$ day $)$ on lipid parameters in a 25 -week, double-blind, randomized trial in 131 patients with hyperlipidemia. ${ }^{*} \mathrm{p}<0.05$ vs placebo. Effects of placebo have been omitted for clarity. Drawn from data presented by Goldberg et al (2000). 
little affected by other currently available lipid-modifying treatments. Table 2 shows the effects of Niaspan ${ }^{\circledR}$ on Lp(a) from randomized, controlled clinical trials.

\section{Niaspan ${ }^{\circledR}$ - statin combination therapy}

Statins remain the mainstay of lipid-modifying therapy according to current guidelines, but exert relatively little effect on HDL-cholesterol, as described above. Many patients will therefore require combination therapy with Niaspan ${ }^{\circledR}$ plus a statin to correct concomitant disturbances of LDLcholesterol and HDL-cholesterol metabolism. A retrospective study analyzed data from 66 dyslipidemic patients prescribed Niaspan ${ }^{\circledR} 1000 \mathrm{mg}$ or $2000 \mathrm{mg}$ for at least 4 weeks in addition to pre-existing statin therapy (Wolfe et al 2001). Increases in HDL-cholesterol after addition of Niaspan ${ }^{\circledR}$ to the regimen were similar to those for Niaspan ${ }^{\circledR}$ monotherapy, described above, with mean increases of $23 \%$ with the $1000 \mathrm{mg}$ dose and $27 \%$ for the $2000 \mathrm{mg}$ dose. Additional reductions in LDL-cholesterol, of $8 \%$ and $31 \%$, respectively vs statin alone, and in triglycerides, of $24 \%$ and $27 \%$ vs statin alone, were also observed. Larger increases in HDL-cholesterol were observed in patients with HDL-cholesterol $<1.0 \mathrm{mmol} /$ $\mathrm{L}(40 \mathrm{mg} / \mathrm{dL})$ at baseline.

Double-blind, randomized, placebo-controlled, doseranging evaluations of various combinations of Niaspan ${ }^{\circledR}$ (500-2500 mg) and a statin (lovastatin 10-40 mg) confirm these observations (Hunninghake et al 2003; Insull et al 2004). Dose-related increases in HDL-cholesterol occurred with increases in the dose of Niaspan ${ }^{\circledR}$ and additional reductions in LDL-cholesterol occurred when Niaspan ${ }^{\circledR}$ $2000 \mathrm{mg}$ was combined with lovastatin $40 \mathrm{mg}$, relative to this dose of statin plus placebo. A third trial (the ADvicor Versus Other Cholesterol-Modulating Agents Trial Evaluation [ADVOCATE] Study) was conducted in 315 hyper- cholesterolemic men or women with HDL-cholesterol $<1.2$ $\mathrm{mmol} / \mathrm{L}(<45 \mathrm{mg} / \mathrm{dL})$ or $<1.3 \mathrm{mmol} / \mathrm{L}(<50 \mathrm{mg} / \mathrm{dL})$, respectively (Bays et al 2003). Patients were randomized to receive open-label Niaspan ${ }^{\circledR}$ - lovastatin combinations (doses up to $1000 \mathrm{mg} / 40 \mathrm{mg}$ or $2000 \mathrm{mg} / 40 \mathrm{mg}$ ) or monotherapy with simvastatin (10-40 mg) or atorvastatin (10-40 mg) for 16 weeks. Larger increases in HDL-cholesterol were observed with Niaspan ${ }^{\circledR}$ - lovastatin $1000 \mathrm{mg} / 40 \mathrm{mg}(+17 \%)$ and $2000 \mathrm{mg} / 40 \mathrm{mg}(+32 \%)$, relative to atorvastatin $40 \mathrm{mg}$ $(+6 \%)$ or simvastatin $40 \mathrm{mg}(+7 \%)$.

Addition of the cholesterol absorption inhibitor, ezetimibe, increases the efficacy of statins on additional lowering of LDL-cholesterol (Robinson and Davidson 2006). The efficacy of this combination was compared with that of Niaspan $^{\circledR}$ - statin combinations in 292 patients indicated for management of LDL-cholesterol according to US cardiovascular management guidelines in a 12-week, randomized trial (McKenney et al 2006). Reductions in LDL-cholesterol were similar between treatments, but Niaspan ${ }^{\circledR}$-rosuvastatin, and Niaspan ${ }^{\circledR}$ - atorvastatin regimens were more effective in increasing HDL-cholesterol and in reducing triglycerides, compared with simvastatin in combination with ezetimibe or rosuvastatin monotherapy (Figure 3).

Dyslipidemia requires lifelong management. The longterm effects of Niaspan ${ }^{\circledR}$, titrated towards a maximum dose of $3000 \mathrm{mg}$, were observed for up to 96 weeks in patients with dyslipidemia, some of whom were previously enrolled in short-term studies (Capuzzi et al 1998; Guyton and Capuzzi 1998). Patients receiving Niaspan ${ }^{\circledR}$ at a dose of $2000 \mathrm{mg}$ or less could also receive a statin or a bile acid sequestrant. Figure 4 shows effects on principal lipid parameters in Niaspan ${ }^{\circledR}$ - treated patients with or without additional statin treatment (the median dose of Niaspan ${ }^{\circledR}$ was $2000 \mathrm{mg}$ in either group). Effects on HDL-cholesterol were essentially

Table 2 Effects of Niaspan ${ }^{\circledR}$ on lipoprotein (a) (Lp(a)) in controlled clinical trials

\begin{tabular}{|c|c|c|c|c|}
\hline \multirow[t]{2}{*}{ Study } & \multirow[t]{2}{*}{ Duration (weeks) } & \multirow[t]{2}{*}{ Target dose of $\operatorname{Niaspan}^{\circledR}(\mathrm{mg})$} & \multicolumn{2}{|c|}{ Mean change in Lp(a) (\%) } \\
\hline & & & Niaspan $^{\circledR}$ & Comparator \\
\hline Morgan et al 1996 & 12 & 2000 & $-27 \dagger$ & 0 (placebo) \\
\hline Knopp et al 1998 & 16 & 1500 & $-24.7^{*}$ & 2.2 (placebo) \\
\hline Grundy et al 2002 & 16 & 1500 & -12 & 3 (placebo) \\
\hline \multirow{2}{*}{ Bays et al 2003} & 16 & 2000 & $-21^{\mathrm{a}, *}$ & 0 (atorvastatin) \\
\hline & & & & -2 (simvastatin) \\
\hline Grundy et al 2004 & 20 & 1500 & $-21^{*}$ & -6 (fenofibrate) \\
\hline \multirow[t]{2}{*}{ McKenney et al 2006} & 12 & 1000 & $-7^{\mathrm{b}, *}$ & 8 (simvastatin + ezetimibe) \\
\hline & & & $-5^{\mathrm{c}, *}$ & II (rosuvastatin) \\
\hline
\end{tabular}

Notes: Studies evaluating Niaspan ${ }^{\circledR}$ at target doses within its therapeutic dose range $(2000 \mathrm{mg} /$ day $)$ are shown. Where more than one dose was evaluated, the largest effect on $L_{p}(a)$ is shown. Significant ( $p<0.05$ or better) vs *comparator or tbaseline. Some trials involved combination of Niaspan ${ }^{\circledR}$ with ${ }^{\text {a }}$ simvastatin, batorvastatin, or ${ }^{~}$ rosuvas-

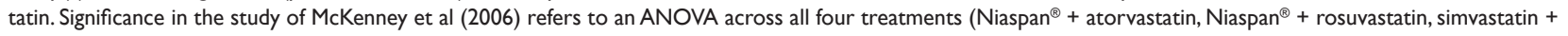
ezetimibe, and rosuvastatin monotherapy). 


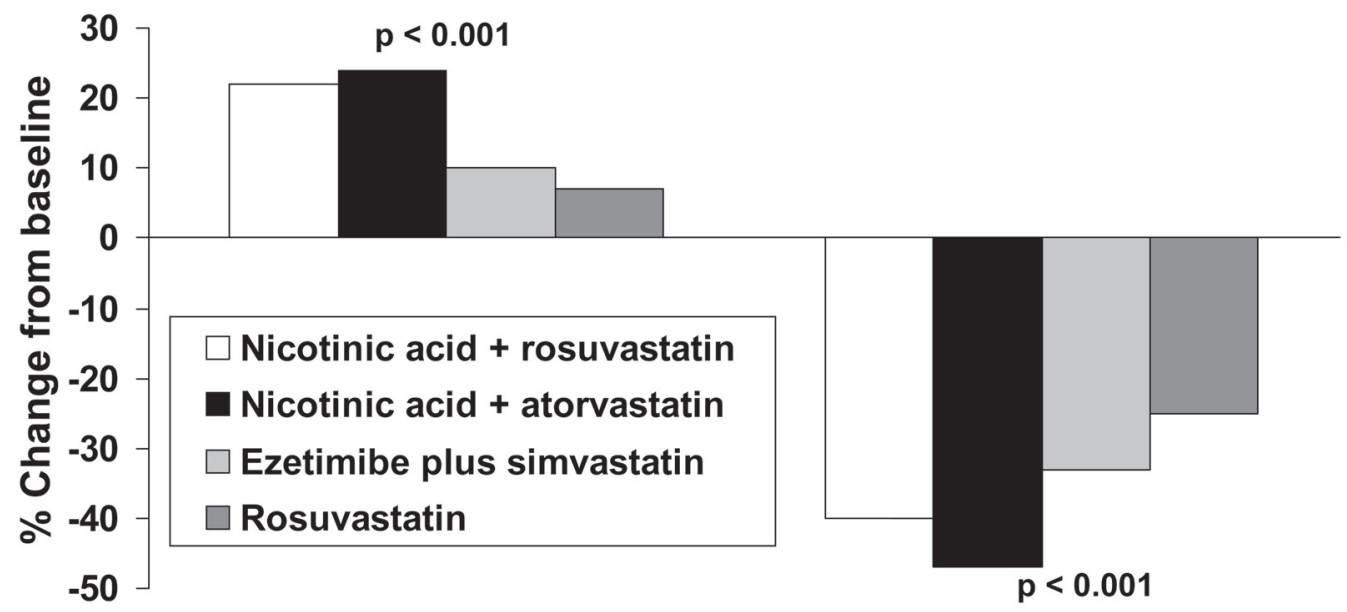

Figure 3 Comparison of effects on lipids of combinations of nicotinic acid with a statin in comparison with a combination of a statin with ezetimibe or rosuvastatin monotherapy in a 12-week, open-label, randomized trial in 292 patients indicated for LDL-cholesterol lowering therapy. Patients received rosuvastatin (20-40 mg), rosuvastatin plus Niaspan ${ }^{\circledR}$ (10/1000 mg or $20 / 1000 \mathrm{mg}$ ), atorvastatin plus Niaspan ${ }^{\circledR}(20 / 1000 \mathrm{mg}$ or $40 / 2000 \mathrm{mg})$, or simvastatin plus ezetimibe (20/10 mg or $\left.40 / 10 \mathrm{mg}\right)$. Significance values are from ANOVA across groups. Drawn from data presented by McKenney et al (2006).

identical between groups, with additional reductions in LDLcholesterol and triglycerides arising from statin treatment.

\section{Efficacy in patients with cardiometabolic comorbidities}

Patients with cardiometabolic comorbidities, such as type 2 diabetes or the metabolic syndrome, are at markedly increased risk of adverse cardiovascular outcomes (Isomaa et al 2001) and require prompt correction of dyslipidemia. The Assessment of Diabetes Control and EValuation of the Efficacy of Niaspan ${ }^{\circledR}$ Trial (ADVENT) involved randomization of 146 type 2 diabetes patients with the atherogenic dyslipidemia phenotype (low HDL-cholesterol and/ or hypertriglyceridemia) to receive double-blind treatment with Niaspan ${ }^{\circledR} 1000 \mathrm{mg}$, Niaspan ${ }^{\circledR} 1500 \mathrm{mg}$ or placebo for 16-weeks (Grundy et al 2002). Mean increases in HDL-

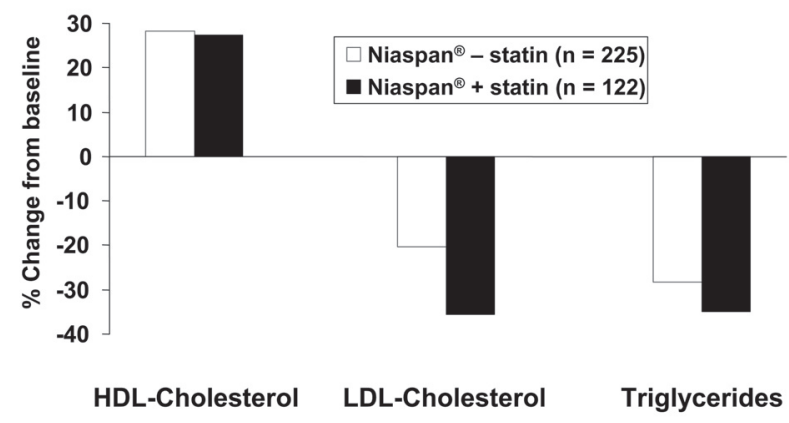

Figure 4 Long-term ( 96 weeks) effects of Niaspan ${ }^{\circledR}$ (up to $3000 \mathrm{mg} /$ day) on the lipid profile in patients with dyslipidemia, with $(n=122)$ or without $(n=225)$ concomitant statin administration. Drawn from data presented by Guyton and Capuzzi (1998). cholesterol at study end in the Niaspan ${ }^{\circledR} 1000 \mathrm{mg}$ and 1500 mg groups were $19 \%$ and $24 \%$, respectively, which were significant $(p<0.05)$ compared with small changes observed on placebo. A further 20-week, double-blind, randomized evaluation compared Niaspan ${ }^{\circledR} 1000 \mathrm{mg}$ and Niaspan ${ }^{\circledR} 1500$ $\mathrm{mg}$, each combined with lovastatin $40 \mathrm{mg}$, with fenofibrate in patients with atherogenic dyslipidemia (HDL-cholesterol $\leq 1.0 \mathrm{mmol} / \mathrm{L}[\leq 40 \mathrm{mg} / \mathrm{dL}]$ in men or $\leq 1.3 \mathrm{mmol} / \mathrm{L}$ $[<50 \mathrm{mg} / \mathrm{dL}]$ in women and triglycerides $\geq 1.7 \mathrm{mmol} / \mathrm{L}$ $[150 \mathrm{mg} / \mathrm{dL}]$ ) (Grundy et al 2004). The mean increase in HDL cholesterol was greater with Niaspan ${ }^{\circledR}$ relative to fenofibrate ( $26 \%$ vs $12 \%$; p < 0.05$)$. The additional potentially beneficial effects on lipid parameters other than HDLcholesterol described above for non-diabetic populations were also observed in both of these studies.

A retrospective analysis presented in abstract form reviewed data from 757 subjects who had received Niaspan ${ }^{\circledR}$ in combination with lovastatin, of whom 347 had the metabolic syndrome (National Cholesterol Education Program criteria) (McGovern et al 2004). Mean increases in HDL-cholesterol were similar in patients with and without the metabolic syndrome ( $36 \%$ vs $32 \%$ ), as were reductions in LDLcholesterol $(-42 \%$ and $-45 \%)$. A slightly larger decrease in triglycerides occurred in patients with vs those without the metabolic syndrome $(-47 \%$ vs $-32 \%, \mathrm{p}<0.05)$.

\section{Lipid sub-profiles}

The atherogenic dyslipidemia phenotype is characterized by a shift in the lipoprotein sub-class distribution towards 
small, dense particles (Goldberg 2001). These are believed to be more atherogenic than larger, more buoyant particles, particularly in the case of small, dense LDL (Goldberg 2001). Thus, an increase in lipoprotein particle size is generally considered to represent a reduction in atherogenicity. A study in 60 patients with primary hypercholesterolemia who received Niaspan ${ }^{\circledR} 1000 \mathrm{mg}$ or $2000 \mathrm{mg}$ for 12 weeks demonstrated an increased proportion of larger HDL particles, and a reduced proportion of small, dense LDL particles (Morgan et al 2003). Other studies have demonstrated increases in the HDL2 subfraction with Niaspan ${ }^{\circledR}$ given either as monotherapy (Knopp et al 1998; Goldberg et al 2000) or in combination with a statin (Van et al 2002; Bays and McGovern 2003).

\section{Tolerability and safety of Niaspan ${ }^{\circledR}$}

Flushing is the main tolerability issue with nicotinic acid, including Niaspan ${ }^{\circledR}$. The frequency of flushing with Niaspan ${ }^{\circledR}$ and immediate-release nicotinic acid was evaluated during 8 weeks of double-blind treatment (Kos Pharmaceuticals/ Merck KGaA, data on file). These data indicated that $72 \%$ of patients flushed once with Niaspan ${ }^{\circledR}$, ie, about $28 \%$ of patients did not report flushing. About $20 \%$ of patients flushed 6 times, ie, about $80 \%$ flushed 5 times or less. The frequency of flushing was lower with Niaspan ${ }^{\circledR}$ than with immediaterelease nicotinic acid. In general, flushing tends to decrease during continued treatment with Niaspan ${ }^{\circledR}$. Flushing can be minimized by taking Niaspan ${ }^{\circledR}$ at bedtime with a low-fat snack, and by avoiding spicy foods or alcohol close to the time of Niaspan ${ }^{\circledR}$ intake. Analgesic doses of a non-steroidal anti-inflammatory agent are effective in terminating flushing episodes.

Niaspan ${ }^{\circledR}$ is not associated with significant hepatic toxicity. Long-term (up to 96 weeks) evaluations of Niaspan ${ }^{\circledR}$ monotherapy $(\mathrm{n}=517)$ or Niaspan ${ }^{\circledR}-$ statin combinations demonstrated an incidence of liver function test abnormalities of $<1 \%$. Similarly, extensive clinical experience with Niaspan ${ }^{\circledR}$ in the USA confirms that the potential of Niaspan ${ }^{\circledR}$ to induce rhabdomyolysis is minimal, whether it is prescribed alone or in combination with a statin. A review of adverse event reporting to the US Food and Drug Administration supports a beneficial safety profile for Niaspan ${ }^{\circledR}$ (Al-Sheikh et al 2005). The incidence of reports of hepatic adverse events with Niaspan $^{\circledR}$ (2 per million prescriptions) was significantly lower than that for commonly used statins, or fibrates. Similarly the incidence of side-effects in musculature was generally similar to, or lower than those reported for these agents.

Double-blind trials in type 2 diabetic populations have shown that the effects of Niaspan ${ }^{\circledR}$ on glycemia are minimal, with changes in $\mathrm{HbA}_{1 \mathrm{C}}$ of $<0.3 \%$ units that can be accommodated by alterations to the antidiabetic regimen (Grundy et al 2002, 2004). However, it is theoretically possible that exacerbation of pre-diabetic dysglycemia might precipitate a diagnosis of clinical type 2 diabetes or the metabolic syndrome. The effects of Niaspan ${ }^{\circledR}$ on fasting glucose in non-diabetic subjects were similar to those of immediaterelease Niaspan ${ }^{\circledR}$ in a comparative, randomized trial, with increases of $4 \%-5 \%$ from baseline at a total dose of nicotinic acid of $1500 \mathrm{mg} /$ day (Knopp et al 1998). Comparable, relatively minor increases in fasting glucose were observed in other randomized evaluations of $\mathrm{Niaspan}^{\circledR}$ in dyslipidemic patients who were non-diabetic or had well-controlled diabetes (Morgan et al 1996; Capuzzi et al 1998), although other studies found no effect, or a transient effect, of Niaspan ${ }^{\circledR}$ on fasting glucose in comparable populations (Goldberg et al 2000; Kashyap et al 2002). One study evaluated Niaspan ${ }^{\circledR}$ in patients with HIV managed with antiretroviral therapy, which often is associated with insulin resistance and associated comorbidities reminiscent of the metabolic syndrome (Sweet 2005). This trial included 23 pre-diabetic patients within its overall population: in this sub-group, there were no cases of prolonged fasting hyperglycemia, and only one case of post-challenge hyperglycemia (measured using an oral glucose tolerance test) after 44 weeks of treatment with Niaspan ${ }^{\circledR}$ at doses up to $2000 \mathrm{mg}$. In conclusion, while minor increases in blood glucose are common with Niaspan ${ }^{\circledR}$ or other nicotinic acid preparations, the overall impact on cardiovascular risk is likely to be minor compared with the potential anti-atherosclerotic benefits of Niaspan ${ }^{\circledR}$, which are described later in this review.

Nicotinic acid also suppresses free fatty acid (FFA) production, which contributes to its effects on the lipid profile, but a rebound in FFA levels often occurs after treatment with immediate-release nicotinic acid (Chapman 2006). We are unaware if such a rebound occurs with Niaspan ${ }^{\circledR}$, and clinical evaluation of this phenomenon is warranted.

\section{The NAUTILUS study: a recent multicentre evaluation of $\mathrm{Niaspan}^{\circledR}$ in a real-life clinical setting Rationale and design of NAUTILUS}

The studies described above provide a detailed account of the efficacy, safety and tolerability of Niaspan ${ }^{\circledR}$, defined mainly within the controlled environments of double-blind, randomized trials. However, the management of dyslipidemia takes place mainly in the routine, usual-care setting. The multi- 
ceNtre, open, uncontrolled sAfety and tolerability stUdy of a modified-release nicoTinic acId formuLation in sUbjects with dyslipidemia and low HDL-cholesterol (NAUTILUS) trial was designed to evaluate $\mathrm{Niaspan}^{\circledR}$ in a realistic environment relevant to the day-to-day care of patients with dyslipidemia, and is thus described separately here. The main purpose of NAUTILUS was to evaluate the safety and tolerability of Niaspan ${ }^{\circledR}$. Effects on lipid parameters were also measured.

NAUTILUS was a multicenter (112 centers), evaluation of open-label Niaspan ${ }^{\circledR}$, administered for 15 weeks (Vogt et al 2006a). Eligible patients had dyslipidemia uncontrolled by 4 weeks of treatment with diet and also had low HDL-cholesterol $(<1.0 \mathrm{mmol} / \mathrm{L}[40 \mathrm{mg} / \mathrm{dL}]$ in men and $<1.2 \mathrm{mmol} / \mathrm{L}$ [50 mg/dL] in women). Diabetes was not an exclusion criterion, although patients with uncontrolled diabetes were excluded. Study treatment was titrated towards a maximum of $2000 \mathrm{mg}$ in stages over 12-15 weeks of treatment, depending on tolerability responses. Down-titration was allowed to resolve tolerability issues, though reduction of the Niaspan ${ }^{\circledR}$ dose to below $750 \mathrm{mg}$, or failure to receive at least one dose of $\mathrm{Niaspan}^{\circledR} 1000 \mathrm{mg}$ resulted in exclusion from the trial.

\section{Main results of NAUTILUS}

A total of 566 patients received treatment. The study population was at elevated cardiovascular risk, on average, with $80 \%$ having at least one cardiovascular comorbidity (hypertension or vascular disease) and 58\% having diabetes. On average, patients at baseline had low HDL-cholesterol (mean HDL-cholesterol was $0.86 \mathrm{mmol} / \mathrm{L}$ [33 mg/dL] in men and $0.99 \mathrm{mmol} / \mathrm{L}$ [38 mg/dL] in women) and hypertriglyceridemia (mean triglycerides were $2.91 \mathrm{mmol} / \mathrm{L}$ [258 mg/dL]), consistent with study inclusion criteria. LDL-cholesterol was not markedly elevated at baseline, with mean values of $2.80 \mathrm{mmol} / \mathrm{L}$ [108 $\mathrm{mg} / \mathrm{dL}]$ in men and $3.24 \mathrm{mmol} / \mathrm{L}[125 \mathrm{mg} / \mathrm{dL}]$ in women.

Niaspan ${ }^{\circledR}$ was generally well tolerated, apart from flushing, the principal tolerability issue with nicotinic acid. Flushing was reported by $42.0 \%$ of patients, although most episodes were mild or moderate in severity. Consistent with these observations, the incidence of treatment withdrawal for flushing was low (9.7\%) and only a minority of patients flushed more than five times (Figure 5), consistent with previous experience with Niaspan ${ }^{\circledR}$, as described above. The incidence of all-cause serious adverse events was also low $(3.7 \%)$, and was related to flushing in $0.2 \%$ of patients. There was no serious hepatic or muscle toxicity.

Mean increases from baseline in HDL-cholesterol in men and women were $22.4 \%$ and $28.1 \%$, respectively, with

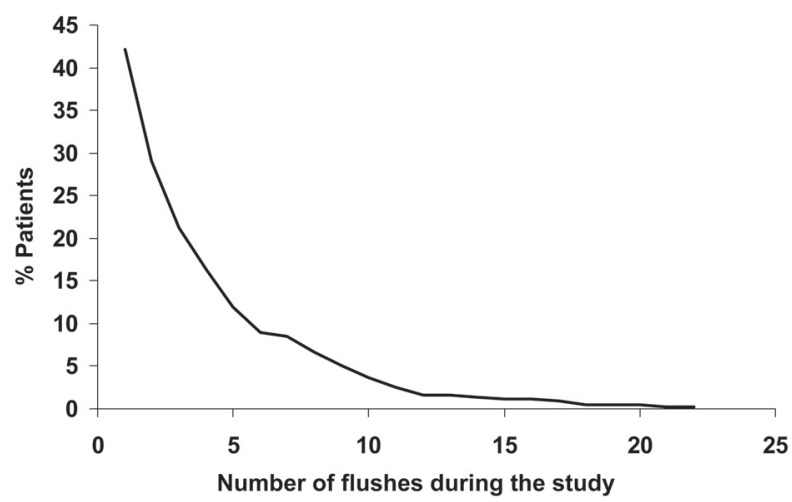

Figure 5 Flushing with Niaspan ${ }^{\circledast}$ in the NAUTILUS trial, a I5-week evaluation of Niaspan ${ }^{\circledR}$ at doses up to $2000 \mathrm{mg} /$ day in 566 patients with dyslipidemia and low HDL-cholesterol managed in the usual care setting. Reproduced with permission from Vogt A, Kassner U, Hostalek U, et al 2006. Evaluation of the safety and tolerability of prolonged-release nicotinic acid in a usual care setting: the NAUTILUS study. Curr Med Res Opin, 22:417-25.

corresponding decreases in triglycerides of $-10.6 \%$ and $-17.1 \%$ (Figure 6).

\section{Results in clinically important patient subgroups}

Subgroup analyses in the NAUTILUS trial included stratification of patients according to gender, the presence of diabetes, metabolic syndrome, hypercholesterolemia or isolated low HDL-cholesterol, receipt/non-receipt of concomitant statin treatment, and age (Vogt et al 2006a, b, c, d). The incidence of flushing or other adverse events did not vary to a clinically significant extent according to age, statin use, or diabetes (flushing was not analyzed separately in the other subgroups listed above). However, older patients were somewhat more likely to withdraw due to flushing ( $15 \%$ vs $7 \%$ ).

Figure 6 shows effects on the main indices of atherogenic dyslipidemia (HDL-cholesterol and triglycerides) from subgroup analyses. Robust improvements in either parameter were observed in all subgroups.

\section{Anti-atherosclerotic effects of Niaspan ${ }^{\circledR}$}

The Arterial Biology for the Investigation of the Treatment Effects of Reducing Cholesterol (ARBITER 2) study, and its follow-up study (ARBITER 3) were designed to explore whether Niaspan ${ }^{\circledR}$ co-administered with a statin expresses the anti-atherogenic actions demonstrated by immediate-release nicotinic acid-statin combinations in the HATS and other trials, described above (Taylor et al 2004, 2006). Patients eligible for these studies had low HDL-cholesterol $(<1.2$ 
a) HDL-cholesterol

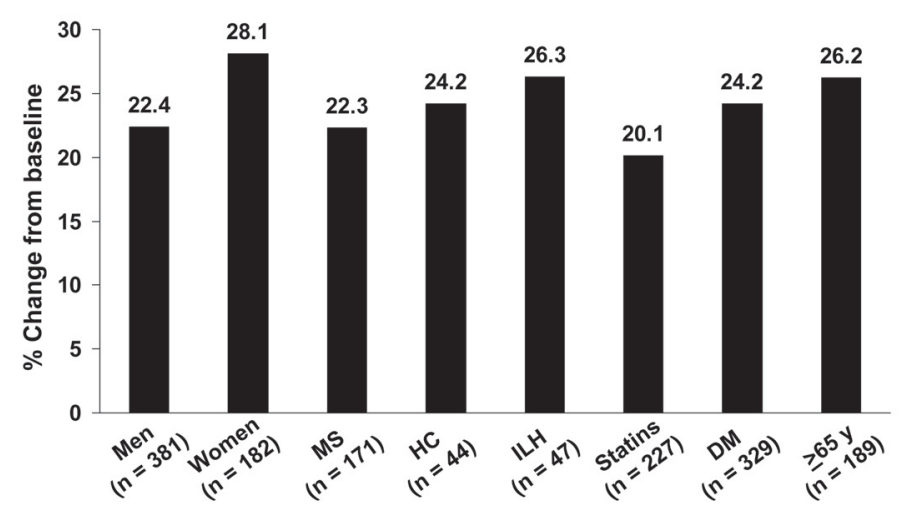

b) Triglycerides

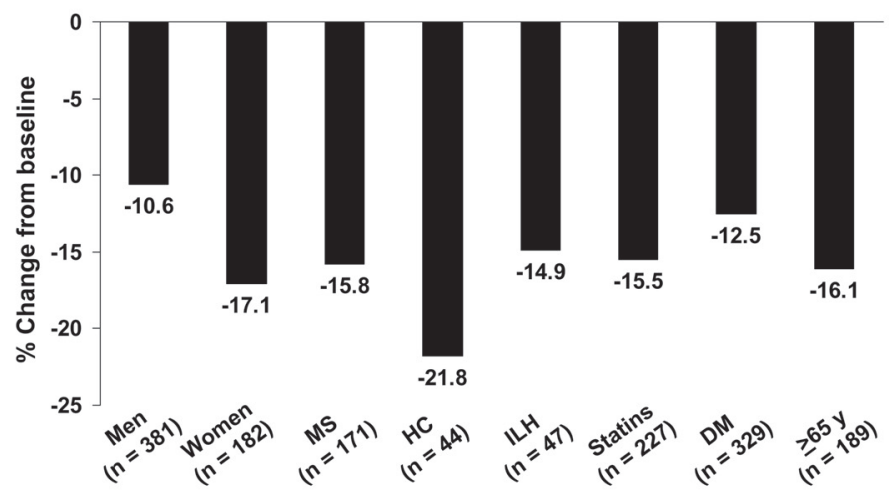

Figure 6 Mean changes in HDL-cholesterol and triglycerides in subgroups of the NAUTILUS population based on gender, presence/absence of the metabolic syndrome (MS), hypercholesterolemia (HC), isolated low HDL-cholesterol (ILH), receipt/non-receipt of statins, presence/absence of diabetes mellitus (DM), and age. Drawn from data presented by Vogt et al 2006a, b, c, d.

$\mathrm{mmol} / \mathrm{L}[46 \mathrm{mg} / \mathrm{dL}])$ despite existing treatment with a statin, and had coronary artery disease.

The ARBITER 2 trial was a randomized, doubleblind, parallel-group study, in which a moderate dose of Niaspan ${ }^{\circledR}(1000 \mathrm{mg})$ was compared with placebo, each being added to pre-existing statin treatment for 1 year. ARBITER 3 was an open-label extension to ARBITER 2. Of 78 patients who completed 1 year of treatment with Niaspan ${ }^{\circledR}$ in ARBITER 2, 69 continued on this treatment for a further year, with 57 patients completing the study (Figure 7). Of 71 patients who received placebo in ARBITER 2, 61 switched to Niaspan ${ }^{\circledR}$ and 47 completed a year of Niaspan ${ }^{\circledR}$ treatment in ARBITER 3 (Figure 7). B-mode ultrasound was used in both phases of the study to measure carotid intima-media thickness (CIMT), an accepted and validated surrogate marker for the overall burden of atherosclerosis (Hodis et al 1998).

One year of treatment with Niaspan ${ }^{\circledR}$ in ARBITER 2 increased mean HDL-cholesterol from $1.0 \mathrm{mmol} / \mathrm{L}$
$(39 \mathrm{mg} / \mathrm{dL})$ to $1.2 \mathrm{mmol} / \mathrm{L}(47 \mathrm{mg} / \mathrm{dL} ; \mathrm{p}<0.001)$, and decreased triglycerides from $1.7 \mathrm{mmol} / \mathrm{L}(154 \mathrm{mg} / \mathrm{dL})$ to $1.5 \mathrm{mmol} / \mathrm{L}(134 \mathrm{mg} / \mathrm{dL} ; \mathrm{p}=0.009)$, while no change in either parameter occurred in the placebo group. The mean value of HDL-cholesterol at the end of ARBITER 3 was similar in groups who had previously received placebo or Niaspan ${ }^{\circledR}$ in ARBITER $2(1.25 \mathrm{mmol} / \mathrm{L}$ [48.5 mg/dL] and $1.26 \mathrm{mmol} / \mathrm{L}$ [48.6 mg/dL], respectively). LDLcholesterol was unchanged by Niaspan ${ }^{\circledR}$, which is not surprising as this parameter was already well controlled in this statin-treated population (mean baseline value 2.3 $\mathrm{mmol} / \mathrm{L}[87.6 \mathrm{mg} / \mathrm{dL}])$.

Effects on atherosclerosis in the ARBITER trials are shown in Table 3. In ARBITER 2, atherosclerosis progressed significantly in patients randomized to receive placebo, while no significant progression of atherosclerosis occurred in the Niaspan ${ }^{\circledR}$ group over 1 year of treatment. In ARBITER 3, atherosclerosis regressed significantly in patients switched from placebo to Nias- 


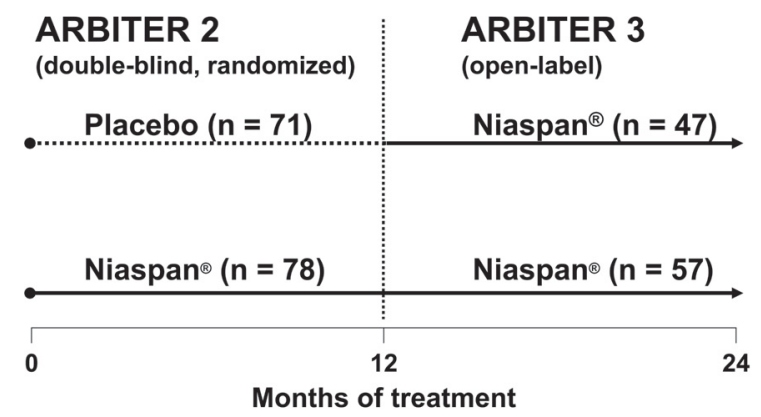

Figure 7 Treatment assignments in the double-blind, randomized,ARBITER 2 study and its open-label follow-up study,ARBITER 3. Numbers of patients shown are those completing each phase. The duration each phase trial was I year; the Niaspan ${ }^{\circledast}$ daily dose was 1000 mg. Adapted with permission from Taylor AJ, Lee HJ, Sullenberger LE. 2006. The effect of 24 months of combination statin and extendedrelease niacin on carotid intima-media thickness:ARBITER 3. Curr Med Res Opin, 22:2243-50.

$\operatorname{pan}^{\circledR}$ and in patients who continued on Niaspan ${ }^{\circledR}$ for another 12 months of treatment. Pooling the data from ARBITER 2 and ARBITER 3 showed that 12 months of Niaspan ${ }^{\circledR}$ in either trial was associated with significant regression of atherosclerosis, relative to 12 months of placebo. Atherosclerosis also regressed to a significant extent relative to placebo in 62 patients with type 2 diabetes or the metabolic syndrome who received Niaspan ${ }^{\circledR}$ for 12 or 24 months.

Changes in CIMT correlated significantly and inversely with changes in HDL-cholesterol $(\mathrm{p}=0.002)$, and multivariate analysis showed that changes in CIMT were significantly and independently related to changes in HDL-cholesterol, but not to changes in triglycerides or LDL-cholesterol. Thus, the ARBITER 2 and ARBITER 3 trials demonstrate that increased HDL-cholesterol during treatment with Niaspan ${ }^{\circledR}$ and a statin was associated with clinically significant anti-atherogenic benefits in patients with coronary artery disease.

\section{Looking ahead: evaluating the effects of Niaspan ${ }^{\circledR}$ on clinical outcomes}

The ARBITER 2 and ARBITER 3 studies were too small to confirm that the clinical outcome benefits observed with a combination of immediate-release nicotinic acid and a statin in the HATS trial translate to Niaspan ${ }^{\circledR}$-based combination therapy. The double-blind, randomized, multicenter Atherothrombosis Intervention in Metabolic Syndrome with Low HDL-C/High Triglyceride and Impact on Global Health Outcomes trial (AIM-HIGH) will address this question. The study hypothesis is that the clinical cardiovascular event rate in patients randomized to Niaspan ${ }^{\circledR}$ plus simvastatin will be lower than that in patients randomized to simvastatin alone during 6 years of treatment, despite levels of LDL-cholesterol being similar in each group.

The study is jointly funded by the US National Institutes of Health and Kos Pharmaceuticals Inc, and is currently recruiting patients. Eligible patients have atherogenic dyslipidemia, characterized by low HDL-cholesterol, defined as $<1.03$ $\mathrm{mmol} / \mathrm{L}(<40 \mathrm{mg} / \mathrm{dL})$ for men and $<1.29(<50 \mathrm{mg} / \mathrm{dL})$ for women (these values change to $<1.08 \mathrm{mmol} / \mathrm{L}$ [42 $\mathrm{mg} / \mathrm{dL}]$ and $<1.37 \mathrm{mmol} / \mathrm{L}$ [53 $\mathrm{mg} / \mathrm{dL}]$, respectively, if already on a statin) and triglycerides $>1.7 \mathrm{mmol} / \mathrm{L}(150 \mathrm{mg} / \mathrm{dL})$. Inclusion criteria for LDL-cholesterol vary according to statin treatment. The primary study endpoint will be a composite of coronary heart disease death, nonfatal myocardial infarction, ischemic stroke, or hospitalization for high-risk acute coronary syndrome with objective evidence of ischemia.

Table 3 Effects of Niaspan ${ }^{\circledR}$ on atherosclerosis in the ARBITER 2 study and in a pooled analysis of data from the ARBITER 2 and ARBITER 3 studies

\begin{tabular}{|c|c|c|c|c|}
\hline & \multicolumn{2}{|l|}{ Niaspan $^{\circledR}$} & \multicolumn{2}{|l|}{ Placebo } \\
\hline & $\begin{array}{l}\text { Mean change in } \\
\text { CIMT (mm) }\end{array}$ & $\mathbf{p}$ & $\begin{array}{l}\text { Mean change in } \\
\text { CIMT(mm) }\end{array}$ & $\mathbf{p}$ \\
\hline ARBITER 2 & $0.014 \pm 0.011$ & 0.23 & $0.044 \pm 0.011$ & $<0.001$ \\
\hline \multicolumn{5}{|l|}{ ARBITER 3} \\
\hline Patients switching from placebo to Niaspan ${ }^{\circledR}(n=47)$ & $-0.095 \pm 0.019$ & $<0.001$ & - & - \\
\hline Patients continuing on Niaspan ${ }^{\circledR}$ for additional 12 months $(n=57)$ & $-0.04 I+0.021$ & 0.001 & - & - \\
\hline \multicolumn{5}{|l|}{ Pooled analysis of ARBITER 2 and ARBITER 3} \\
\hline First 12 months of Niaspan ${ }^{\circledR}$ in ARBITER 2 or ARBITER $3(n=125)$ & $-0.027 \pm 0.011$ & $<0.001$ & - & - \\
\hline \multicolumn{5}{|l|}{ I2-24 months of Niaspan ${ }^{\circledR}$ in patients with type 2 diabetes or } \\
\hline the metabolic syndrome $(n=62)$ & $-0.046 \pm 0.131$ & $<0.001$ & - & - \\
\hline
\end{tabular}

Notes: Significance values for ARBITER 2 are relative to baseline, while significance values for ARBITER 3 or the pooled analysis of ARBITER 2 and ARBITER 3 are relative to the placebo phase of ARBITER 2. Compiled from data presented by Taylor et al $(2004,2006)$.

Abbreviations: CIMT, carotid intima-media thickness. 


\section{Summary and conclusions}

The burden of cardiovascular morbidity and mortality remains unacceptably high despite widespread use of statins to control LDL-cholesterol. Low HDL-cholesterol is common among patients managed for dyslipidemia and represents an important and under treated source of elevated cardiometabolic risk. Nicotinic acid, the most powerful agent currently available for the correction of low HDLcholesterol, has been shown in well-designed clinical trials to inhibit the progression of atherosclerosis and to reduce cardiovascular event rates in patients at high risk of adverse cardiovascular outcomes. Niaspan ${ }^{\circledR}$ provides a practical and convenient means of administering nicotinic acid, with once-daily administration and a superior tolerability and/or safety profile compared with other formulations of nicotinic acid. The ARBITER 2 and ARBITER 3 studies suggested that the antiatherogenic benefits of nicotinic acid translate to Niaspan $^{\circledR}$, and the AIM-HIGH study will define the cardioprotective potential of $\mathrm{Niaspan}^{\circledR}$-statin combination therapy relative to statin monotherapy.

\section{References}

AIM-HIGH trial, www.clinicaltrials.gov identifier NCT00120289.

Al-Sheikh AA, Karas RH. 2005. Relative safety of lipid altering drugs in the general population. Abstract 3707, presented at the 2005. American Heart Association Scientific Sessions, Dallas, Texas, USA, Nov 13-6, 2005.

Assmann G, Schulte H, von Eckardstein A, et al. 1996. High-density lipoprotein cholesterol as a predictor of coronary heart disease risk. The PROCAM experience and pathophysiological implications for reverse cholesterol transport. Atherosclerosis, 124(Supp 1):S11-20.

Balkau B, Charles MA, Drivsholm T, et al. 2002. Frequency of the WHO metabolic syndrome in European cohorts, and an alternative definition of an insulin resistance syndrome. Diabetes Metab, 28:364-76.

Bays HE, Dujovne CA, McGovern ME, et al. 2003. Comparison of once-daily, niacin extended-release/lovastatin with standard doses of atorvastatin and simvastatin (the ADvicor Versus Other CholesterolModulating Agents Trial Evaluation [ADVOCATE]). Am J Cardiol, 91:667-72.

Bays HE, McGovern ME. 2003. Once-daily niacin extended release/ lovastatin combination tablet has more favorable effects on lipoprotein particle size and subclass distribution than atorvastatin and simvastatin. Prev Cardiol, 6:179-88.

Brown BG, Zhao X-Q, Chait A, et al. 2001. Simvastatin and niacin, antioxidant vitamins, or the combination for the prevention of coronary disease. $N$ Engl J Med, 345:1583-92.

Brown G, Albers JJ, Fisher LD, et al. 1990. Regression of coronary artery disease as a result of intensive lipid-lowering therapy in men with high levels of apolipoprotein B. N Engl J Med, 323:1289-98.

Bruckert E, Baccara-Dinet M, McCoy F, et al. 2005a. High prevalence of low HDL-cholesterol in a pan-European survey of 8545 dyslipidaemic patients. Curr Med Res Opin, 21:1927-34.

Bruckert E, Pamphile R, McCoy F, et al. 2005b. Defining the prevalence of low HDL-C in a European cohort of dyslipidaemic patients. European Heart J Suppl, F23-6.

Bruckert E, Baccara-Dinet M, Eschwege E. 2007. Low HDL-cholesterol is highly prevalent among European type 2 diabetes patients receiving treatment for dyslipidaemia: data from a pan-European survey. Diabet Med. In press.
Canner PL, Berge KG, Wenger NK, et al. 1986. Fifteen-year mortality in Coronary Drug Project patients: long-term benefit with niacin. $J \mathrm{Am}$ Coll Cardiol, 8:1245-55.

Canner PL, Furberg CD, Terrin ML, et al. 2005. Benefits of niacin by glycemic status in patients with healed myocardial infarction (from the Coronary Drug Project). Am J Cardiol, 95:254-7.

Canner PL, Furberg CD, McGovern ME. 2006. Benefits of niacin in patients with versus without the metabolic syndrome and healed myocardial infarction (from the Coronary Drug Project). Am J Cardiol, 97:477-9.

Capuzzi DM, Guyton JR, Morgan JM, et al. 1998. Efficacy and safety of an extended-release niacin (Niaspan): a long-term study. Am J Cardiol, 82:74U-81U.

Cashin-Hemphill L, Mack WJ, Pogoda JM, et al. 1990. Beneficial effects of colestipol-niacin on coronary atherosclerosis. A 4-year follow-up. JAMA, 264:3013-7.

Castelli WP, Garrison RJ, Wilson PW, et al. 1986. Incidence of coronary heart disease and lipoprotein cholesterol levels. The Framingham Study. JAMA, 256:2835-8.

Castelli WP. 1988. Cholesterol and lipids in the risk of coronary artery diseasethe Framingham Heart Study. Can J Cardiol, 4 (Suppl A):5A-10A.

[CDP] Coronary Drug Project Research Group. 1975. Clofibrate and niacin in coronary heart disease. JAMA, 231:360-81.

Chapman MJ. 2006. How does nicotinic acid modify the lipid profile? Eur Heart J Suppl, 8:F54-9.

Dalton TA, Berry RS. 1992. Hepatotoxicity associated with sustained-release niacin. Am J Med, 93:102-4.

Dominguez LJ, Galioto A, Ferlisi A, et al. 2006. Ageing, lifestyle modifications, and cardiovascular disease in developing countries. $J$ Nutr Health Aging, 10:143-9.

Drexel H, Aczel S, Marte T, et al. 2005. Is atherosclerosis in diabetes and impaired fasting glucose driven by elevated LDL cholesterol or by decreased HDL cholesterol? Diabetes Care, 28:101-7.

Dube MP, Wu JW, Aberg JA, et al. 2006. Safety and efficacy of extendedrelease niacin for the treatment of dyslipidaemia in patients with HIV infection: AIDS Clinical Trials Group Study A5148. Antivir Ther, 11:1081-9.

Expert Panel on Detection, Evaluation, and Treatment of High Blood Cholesterol in Adults. 2001. Executive Summary of The Third Report of The National Cholesterol Education Program (NCEP) Expert Panel on Detection, Evaluation, And Treatment of High Blood Cholesterol In Adults (Adult Treatment Panel III). JAMA, 285:2486-97.

Ford ES, Giles WH, Dietz WH. 2002. Prevalence of the metabolic syndrome among US adults: findings from the third National Health and Nutrition Examination Survey. JAMA, 287:356-9.

Frick MH, Elo O, Haapa K, et al. 1987. Helsinki Heart Study: primary-prevention trial with gemfibrozil in middle-aged men with dyslipidemia. Safety of treatment, changes in risk factors, and incidence of coronary heart disease. $N$ Engl J Med, 317:1237-45.

Goldberg A, Alagona P Jr, Capuzzi DM, et al. 2000. Multiple-dose efficacy and safety of an extended-release form of niacin in the management of hyperlipidemia. Am J Cardiol, 85:1100-5.

Goldberg IJ. 2001. Clinical review 124: Diabetic dyslipidemia: causes and consequences. J Clin Endocrinol Metab, 86:965-71.

Goldbourt U, Yaari S, Medalie JH. 1997. Isolated low HDL cholesterol as a risk factor for coronary heart disease mortality. A 21-year follow-up of 8000 men. Arterioscler Thromb Vasc Biol, 17:107-13.

Gordon DJ, Probstfield JL, Garrison RJ. 1989. High-density lipoprotein cholesterol and cardiovascular disease. Four prospective American studies. Circulation, 79:8-15.

Gordon T, Castelli WP, Hjortland MC, et al. 1977. High density lipoprotein as a protective factor against coronary heart disease. The Framingham Study. Am J Med, 62:707-14.

Grundy SM, Vega GL, McGovern ME, et al. 2002. Efficacy, safety, and tolerability of once-daily niacin for the treatment of dyslipidemia associated with type 2 diabetes: results of the Assessment of Diabetes Control and Evaluation of the Efficacy of Niaspan Trial. Arch Intern Med, 162:1568-76. 
Grundy SM, Vega GL, McGovern ME, et al. Comparative effects on lipids and glycemic control of niacin extended-release/lovastatin or fenofibrate in patients with diabetic dyslipidemia. Abstract 29-LB, presented at the 64th Scientific Sessions of the American diabetes Association, June 4-8 2004, Orlando, Florida, USA.

Guyton JR, Capuzzi DM. 1998. Treatment of hyperlipidemia with combined niacin-statin regimens. Am J Cardiol, 82:82U-84U.

Hansel B, Giral P, Nobecourt E, et al. 2004. Metabolic syndrome is associated with elevated oxidative stress and dysfunctional dense high-density lipoprotein particles displaying impaired antioxidative activity. $J$ Clin Endocrinol Metab, 89:4963-71.

Hodis HN, Mack WJ, LaBree L, et al. 1998. The role of carotid arterial intima-media thickness in predicting clinical coronary events. Ann Intern Med, 128:262-9.

Hunninghake DB, McGovern ME, Koren M, et al. 2003. A dose-ranging study of a new, once-daily, dual-component drug product containing niacin extended-release and lovastatin. Clin Cardiol, 26:112-8.

Insull W, McGovern ME, Schrott H, et al. 2004. Efficacy of extendedrelease niacin with lovastatin for hypercholesterolemia assessing all reasonable doses with innovative surface graph analysis. Arch Intern Med, 164:1121-7.

Isomaa B, Almgren P, Tuomi T, et al. 2001. Cardiovascular morbidity and mortality associated with the metabolic syndrome. Diabetes Care, 24:683-9.

Kane JP, Malloy MJ, Ports TA, et al. 1990. Regression of coronary atherosclerosis during treatment of familial hypercholesterolemia with combined drug regimens. JAMA, 264:3007-12.

Kashyap ML, McGovern ME, Berra K, et al. 1998. Long-term safety and efficacy of a once-daily niacin/lovastatin formulation for patients with dyslipidemia. Am J Cardiol, 89:672-8.

Kastelein JJP. 2005. The realities of dyslipidaemia: what do the studies tell us? Eur Heart J Suppl, 7:F27-33.

Keech A, Simes RJ, Barter P, et al. 2005. Effects of long-term fenofibrate therapy on cardiovascular events in 9795 people with type 2 diabetes mellitus (the FIELD study): randomised controlled trial. Lancet, 366:1849-61.

Knopp RH, Alagona P, Davidson M, et al. 1998. Equivalent efficacy of a timerelease form of niacin (Niaspan) given once-a-night versus plain niacin in the management of hyperlipidemia. Metabolism, 47:1097-104.

McGovern ME, Malott CM, Simmons PD, et al. 2004. Once-daily niacin-extended-release/lovastatin combination is effective and safe for treatment of dyslipidaemia associated with metabolic syndrome. Abstract 820-5, Scientific session of the American College of Cardiology.

McKenney JM, Jones PH, Bays HE, et al. 2007. Comparative effects on lipid levels of combination therapy with a statin and extended-release niacin or ezetimibe versus a statin alone (the COMPELL study). Atherosclerosis. Epub ahead of print.

Miller NE, Hammett F, Saltissi S, et al. 1981. Relationship of angiographically defined coronary artery disease to plasma lipoprotein subfractions and apolipoproteins. $\mathrm{Br}$ Med J, 282:1741-4.

Morgan JM, Capuzzi DM, Baksh RI, et al. 2003. Effects of extended-release niacin on lipoprotein subclass distribution. Am J Cardiol, 91:1432-6.

Morgan JM, Capuzzi DM, Guyton JR, et al. 1996. Treatment effect of Niaspan, a controlled-release niacin, in patients with hypercholesterolemia: a placebo-controlled trial. J Cardiovasc Pharmacol Ther, 1:195-202.

Niskanen L, Turpeinen A, Penttila I, et al. 1998. Hyperglycemia and compositional lipoprotein abnormalities as predictors of cardiovascular mortality in type 2 diabetes: a 15 -year follow-up from the time of diagnosis. Diabetes Care, 21:1861-9.

Pieper JA. 2002. Understanding niacin formulations. Am J Manag Care, 8(Suppl 12):S308-14.

Pocock SJ, Shaper AG, Phillips AN. 1989. Concentration of high density lipoprotein cholesterol, triglycerides, and total cholesterol in ischaemic heart disease. Br Med J, 298:998-1002.
Raymond SU, Leeder S, Greenberg HM. 2006. Obesity and cardiovascular disease in developing countries: a growing problem and an economic threat. Curr Opin Clin Nutr Metab Care, 9:111-6.

Robinson JG, Davidson MH. 2006. Combination therapy with ezetimibe and simvastatin to achieve aggressive LDL reduction. Expert Rev Cardiovasc Ther, 4:461-76.

Rubins HB, Robins SJ, Collins D, et al. 1999. Gemfibrozil for the secondary prevention of coronary heart disease in men with low levels of high-density lipoprotein cholesterol. Veterans Affairs High-Density Lipoprotein Cholesterol Intervention Trial Study Group. $N$ Engl $J$ Med, 341:410-8.

Sharrett AR, Ballantyne CM, Coady SA. 2001. Coronary heart disease prediction from lipoprotein cholesterol levels, triglycerides, lipoprotein(a), apolipoproteins A-I and B, and HDL density subfractions: The Atherosclerosis Risk in Communities (ARIC) Study. Circulation, 104:1108-13.

Sweet DE. Metabolic complications of antiretroviral therapy. 2005. Top HIV Med, 13:70-4.

Taylor AJ, Lee HJ, Sullenberger LE. 2006. The effect of 24 months of combination statin and extended-release niacin on carotid intima-media thickness: ARBITER 3. Curr Med Res Opin, 22:2243-50.

Taylor AJ, Sullenberger LE, Lee HJ, et al. 2004. Arterial Biology for the Investigation of the Treatment Effects of Reducing Cholesterol (ARBITER) 2: a double-blind, placebo-controlled study of extended-release niacin on atherosclerosis progression in secondary prevention patients treated with statins. Circulation, 110:3512-7.

Third Joint Task Force of European and other Societies on Cardiovascular Disease Prevention in Clinical Practice (constituted by representatives of eight societies and by invited experts). 2003. European guidelines on cardiovascular disease prevention in clinical practice. Eur J Cardiovasc Prev Rehabil, 10:S1-S10.

Turner RC, Millns H, Neil HA, et al. 1998. Risk factors for coronary artery disease in non-insulin dependent diabetes mellitus: United Kingdom Prospective Diabetes Study (UKPDS: 23). BMJ, 316:823-8.

Van JT, Pan J, Wasty T, et al. 2002. Comparison of extended-release niacin and atorvastatin monotherapies and combination treatment of the atherogenic lipid profile in diabetes mellitus. Am J Cardiol, 89:1306-8.

Vogt A, Kassner U, Hostalek U, et al. 2006a Evaluation of the safety and tolerability of prolonged-release nicotinic acid in a usual care setting: the NAUTILUS study. Curr Med Res Opin, 22:417-25.

Vogt A, Kassner U, Hostalek U, et al. 2006b NAUTILUS (safety and tolerability of Niaspan ${ }^{\circledR}$ ): a subgroup analysis of patients with diabetes. $\mathrm{Br}$ J Diabetes Vasc Dis, 6:127-33.

Vogt A, Kassner U, Hostalek U, et al. 2006c Safety and tolerability of prolonged-release nicotinic acid in patients aged $>65$ years enrolled in NAUTILUS. Br J Cardiol, 13:278-82.

Vogt A, Kassner U, Hostalek U, et al. 2006d. Safety and tolerability of prolonged-release nicotinic acid combined with a statin in NAUTILUS. Br J Cardiol, 13:273-7.

Whitney EJ, Krasuski RA, Personius BE, et al. 2005. A randomized trial of a strategy for increasing high-density lipoprotein cholesterol levels: effects on progression of coronary heart disease and clinical events. Ann Intern Med, 142:95-104.

Wilson PW, Abbott RD, Castelli WP. 1988. High density lipoprotein cholesterol and mortality. The Framingham Heart Study. Arteriosclerosis, 8:737-41.

Wolfe ML, Vartanian SF, Ross JL, et al. 2001. Safety and effectiveness of niaspan when added sequentially to a statin for treatment of dyslipidemia. Am J Cardiol, 87:476-9.

Yusuf S, Hawken S, Ounpuu S, et al. 2004. Effect of potentially modifiable risk factors associated with myocardial infarction in 52 countries (the INTERHEART study): case-control study. Lancet, 364:937-52. 
